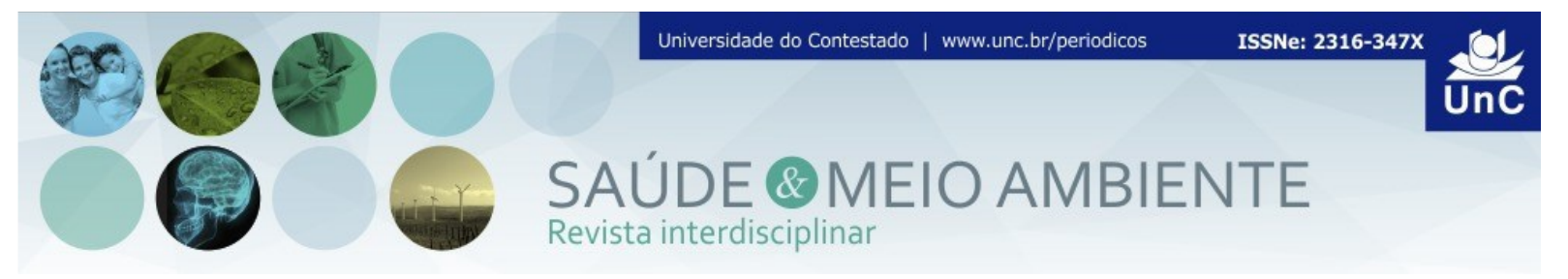

\title{
AVALIAÇÃO MICROBIOLÓGICA DAS TÉCNICAS DE HIGIENIZAÇÃO EMPREGADAS EM ÓCULOS 3D, REUTILIZÁVEIS EM CINEMAS DE SALVADOR, BAHIA
}

\section{MICROBIOLOGICAL EVALUATION OF HYGIENE TECHNIQUES USED IN 3D GLASSES, REUSABLE FROM CINEMAS IN SALVADOR, BAHIA}

\author{
Maiana Souza Silva ${ }^{1}$ \\ Rodrigo Almeida Ferreira ${ }^{2}$ \\ Caroline Alves Feitosa ${ }^{3}$ \\ Sidney Carlos de Jesus Santana ${ }^{4}$ \\ Edson Ruy da Silva Félix ${ }^{5}$
}

\begin{abstract}
RESUMO
Introdução: Os novos sistemas de projeção 3D em cinemas trouxeram adequações aos óculos, passando a ser reutilizáveis e não mais descartáveis. Assim, surgiram questionamentos a respeito de possíveis infecções cruzadas a partir dessa reutilização. Apesar da obrigatoriedade legal da higienização dos óculos, esta é deixada a critério dos próprios cinemas. Objetivo: Esse artigo tem como objetivo avaliar a efetividade da higienização empregada em óculos 3D de cinemas em Salvador, Bahia. Metodologia: As coletas das amostras para análises microbiológicas foram realizadas em óculos 3D não higienizados e higienizados, considerando as formas de higienização empregada nestes (manual e automatizada), sendo analisadas bactérias Gram negativas e Gram positivas, além de coliformes termotolerantes. Resultados: Foram identificados 12 microrganismos dentre as amostras analisadas. Foi observada diferença significativa na frequência de bactérias entre óculos higienizados e não higienizados, porém não houve diferença significativa quanto ao método de higienização. Discussão: as bactérias mais frequentemente encontradas fazem parte da microbiota da superfície ocular, porém em determinadas
\end{abstract}

\footnotetext{
${ }^{1}$ Graduada em Biomedicina pela Escola Bahiana de Medicina e Saúde Pública. Bahia. Brasil. E-mail: maianasilva13.2@bahiana.edu.br

2 Graduado em Biomedicina pela Escola Bahiana de Medicina e Saúde Pública. Atualmente é analista clínico - Maternidade de Referência Professor José Maria de Magalhães Netto. Bahia. Brasil. E-mail: rodrigoalmeidafr@gmail.com

${ }^{3}$ Graduada em Psicologia pela Universidade Federal da Bahia, Mestre em Epidemiologia pela London School of Hygiene and Tropical Medicine, como bolsista da Wellcome Trust, UK, e Doutorado em Saúde Coletiva, ISC/UFBA. Professora adjunta da Escola Bahiana de Medicina e Saúde Pública (EBMSP). Bahia. Brasil. E-mail: carolinefeitosa@bahiana.edu.br

${ }^{4}$ Graduado em Ciências Biológicas pela Universidade Católica do Salvador. Mestre em Ecologia e Biomonitoramento e Doutor em Química Ambiental pela Universidade Federal da Bahia (UFBA). Professor adjunto da Escola Bahiana de Medicina e Saúde Pública (EBMSP). Bahia. Brasil. E-mail: scjsantana@bahiana.edu.br

5 Licenciado em Ciências Biológicas pela Universidade Católica do Salvador e Bacharel Ciências Biológicas pela Universidade Federal da Bahia em Zoologia, Modalidade Organismos Aquáticos. Especialista em Biologia Sanitária e Ambiental pelo CRBIO - 5. Mestre em Ecologia e Biomonitoramento pela Universidade Federal da Bahia. Professor assistente da Escola Bahiana de Medicina e Saúde Pública (EBMSP). Bahia. Brasil. E-mail: edsonruy@bahiana.edu.br
} 
condições podem se tornar patogênicas oferecendo riscos ao seu hospedeiro. Conclusão: o microrganismo mais frequente nos óculos 3D é Staphylococcus coagulase negativo; a higienização apresenta redução significante na frequência de microrganismos, seja por método manual ou automatizado.

Palavras-chave: Óculos. Cinema. Higienização. Contaminação. Bactérias.

\begin{abstract}
Introduction: The new 3D projection systems in movie theaters have brought suitability to the glasses, becoming reusable and no longer disposable. Thus, questions arise about possible cross-infections from this re-use. Despite the legal obligation, the sanitization of the glasses is left under the responsibility of the movie theaters. Aims: This paper aims to evaluate the effectiveness of hygiene technics used in 3D glasses in movie theaters in Salvador, Bahia. Methodology: Samples were collected for microbiological analysis in not sanitized and sanitized 3D glasses, considering the forms of sanitization used in these (manual and automated), were analyzed the Gram negative and Gram positive bacteria, as well as thermotolerant coliforms. Results: Twelve microorganisms were identified from the analyzed samples. A significant difference was observed in the frequency of bacteria between sanitized and not sanitized glasses, but there was no significant difference regarding the sanitization method. Discussion: The bacterium most frequently found are part of the microbiota of the ocular surface, but in certain conditions they may become pathogenic, causing risks to their host. Conclusion: The most frequent microorganism in 3D glasses is coagulase negative Staphylococcus; The not sanitized presents a significant reduction in the frequency of microorganisms in both methods, manual or automated.
\end{abstract}

Keywords: Glasses. Movie Theater. Sanitization. Contamination. Bacteria.

\title{
INTRODUÇÃO
}

A exibição de filmes em três dimensões (3D) data do meado de 1910, entretanto, foi em 1950 que o efeito passou a ser mais utilizado na tentativa de atrair público para as telas de cinemas, sendo deixada de lado devido ao surgimento da televisão. Após anos em desuso, o formato 3D ressurgiu com o lançamento do filme "Avatar" em 2009, graças aos aprimoramentos que proporcionaram efeitos mais reais aos espectadores, o que refletiu no aumento da produção e exibição de filmes nesse formato desde então ${ }^{(1,2)}$

Os novos sistemas de projeção em terceira dimensão trouxeram com eles necessidades de adequações aos óculos utilizados para captação dos efeitos, estes passando a ser reutilizáveis e não mais descartáveis ao final das sessões. Por conseguinte, surgem questionamentos a respeito de possíveis infecções cruzadas a 
partir dessa reutilização, principalmente após a ocorrência de surtos contagiosos que possam estar associados ao uso de óculos 3D, conforme foi descrito em estudo recente sobre a existência de microrganismos patogênicos oportunistas na superfície destes acessórios em cinemas. ${ }^{(3)}$

Assim, no intuito de minimizar os riscos de transmissão de microrganismos em cinemas no Brasil, em razão do reuso desses óculos, foi apresentado um Projeto de Lei Federal $n .^{\circ} 3505 / 2012$ que visa obrigar os cinemas brasileiros a higienizarem os óculos 3D fornecidos aos espectadores após cada sessão. Este foi aprovado apenas em 2015 na Comissão de Seguridade Social e Família da Câmara dos Deputados, se esperando que siga ao Plenário. Porém, leis municipais sobre o tema já se encontram em vigor em alguns municípios, a exemplo a Lei municipal de Salvador n. ${ }^{\circ}$ 8.642/2014 que dispõe da mesma obrigatoriedade. ${ }^{(4,5)}$

Apesar da obrigatoriedade preconizada pela lei supracitada, o modo como a higienização em óculos 3D deve ser feita é deixado a critério dos próprios cinemas sem que haja a exigência de algum controle ou comprovação da eficácia do processo empregado, o que pode acarretar na falta de padronização quanto a técnica mais segura de higiene a ser empregada, exigindo maiores esforços nas ações de controle sanitário que sejam capazes de eliminar, diminuir ou prevenir possíveis riscos à saúde.

Desta forma, frente ao desconhecimento das formas e condições de higienizações dos óculos 3D de modo geral, acredita-se que a realização de estudos de avalição da microbiota envolvida no processo de reutilização desse equipamento venha a ser importante, trazendo à luz os possíveis riscos associados ao seu reuso considerando a forma e condição de higienização que vem sendo empregada pelos cinemas. Vale lembrar que existe uma variedade de microrganismos que potencialmente podem ser transferidos entre usuários de objetos no cotidiano, resultando em doenças como infecções oculares, a exemplo da conjuntivite por ação de bactérias patogênicas. ${ }^{(6,7)}$

Estudos relatam que mãos e superfícies inanimadas, quando contaminadas, podem se tornar fonte de transmissão de microrganismos patogênicos, sendo que muitos destes podem permanecer em determinadas superfícies por meses caso não seja realizada uma desinfecção adequada. ${ }^{(8,9)}$

Desta forma, tendo em vista a carência de parâmetros sanitários que referendem a eficiência dos procedimentos de higienização atualmente empregados para os óculos 3D em cinemas e da falta de métodos padronizados para esta verificação, o presente estudo tem por objetivo promover uma avaliação microbiológica da efetividade na higienização empregada em óculos 3D de cinemas em Salvador, Bahia. Além disso, se objetiva também caracterizar a microbiota presente nesses equipamentos, comparando a qualidade das técnicas de higienização empregadas. 


\section{METODOLOGIA}

A primeira etapa das análises consistiu no estudo realizado no período entre novembro de 2014 a novembro de 2015, correspondendo a uma pesquisa bacteriológica qualiquantitativa, comparativa da condição e métodos de higienização em óculos $3 \mathrm{D}$, monitorados em seis cinemas entre três diferentes empresas que oferecem exibição de filmes em 3D dentre os quinze cinemas encontrados em Salvador, Bahia até 2017.

As coletas das amostras foram realizadas em óculos 3D não higienizados (Devolvidos pelo público após uso) e higienizados (Limpos para entrega ao público), considerando diferentes formas ou métodos de higienização empregados pelos cinemas (manual e automatizada). O material microbiológico foi coletado a partir da fricção de Swab nas faces internas das lentes e ponte dos óculos e transportado em meio Stuart ao Laboratório Central de Saúde Pública do Município de Salvador, Bahia (LACEN-Salvador), posteriormente semeado em meio Ágar sangue. As culturas foram incubadas a $37^{\circ} \mathrm{C}$ em condição aeróbia.

As identificações das bactérias foram feitas em nível espécie para as Gram negativas e em gênero para as Gram positivas, sempre que possível. Foram utilizadas provas de Gram, Catalase e Coagulase, provas bioquímicas com os meios contidos no kit Enterokit B (EPM, MILI e Citrato) e Kit NF para as bactérias não-fermentadoras, ambos da marca PROBAC.

A partir dos resultados obtidos nas amostras de bactérias anteriormente analisadas, numa segunda etapa três cinemas, dentre os seis anteriormente avaliados, foram selecionados para pesquisa de coliformes termotolerantes em óculos. Foram coletadas então amostras no período de junho de 2016, a partir da imersão individual dos óculos higienizados e não higienizados em sacos estéreis contendo $100 \mathrm{ml}$ de água peptonada a $0,001 \%$, seguindo metodologia adaptada de Merriman e colaboradores ${ }^{10}$. Após fricção dos óculos pela face externa dos sacos estéreis, estes foram devolvidos aos cinemas para posterior lavagem. Os microrganismos capturados nos caldos estéreis foram encaminhados ao laboratório da Escola Bahiana de Medicina e Saúde Pública, à temperatura aproximada de $10^{\circ} \mathrm{C}$ para análises.

No laboratório as amostras permaneceram à temperatura ambiente por $18 \mathrm{~h}+/$ $2 \mathrm{~h}$ e posteriormente filtradas em membrana filtrante. Em seguida foram incubadas em meio $\mathrm{mFC}$ por $24 \mathrm{~h}$ à $37^{\circ} \mathrm{C}$, que apresenta um crescimento diferencial para colônias de coliformes. Foram classificadas como positivas para coliformes termotolerantes quando apresentavam crescimento de colônias azuis e negativas quando apresentavam crescimento de colônias atípicas as quais apresentam coloração diferente da azul e na ausência de colônias. 


\section{ANÁLISE ESTATÍSTICA}

Os dados foram analisados descritivamente, sendo realizado inicialmente o cálculo das frequências simples e relativas de amostras positivas e negativas. Além disso, foram apresentadas também as frequências de amostras positivas segundo estado de higienização dos óculos (higienizados e não higienizados), assim como a forma de higienização (manual e automatizada). A análise da associação entre as variáveis foi realizada através do teste do chi-quadrado de Pearson, e do teste exato de Fisher, quando necessário.

Todas as análises adotaram um nível de significância de 0,05 e foram realizadas no software SPSS Statistics (Versão 22).

Como nenhuma coleta de amostras ou dados envolveu seres humanos, não houve necessidade de aprovação pelo Comitê de Ética em Pesquisa.

\section{RESULTADOS}

Durante as análises foram identificados dois tipos de higienização, dentre os cinemas avaliados: o método manual, realizado em tanques de lavagem onde os óculos são submersos em soluções contendo detergentes e sanitizantes, seguindo orientações pré-estabelecidas pelos fabricantes; e o método automatizado onde se utiliza máquina do tipo lava louça, onde os óculos são submetidos à lavagem em temperatura de $60^{\circ} \mathrm{C}$, com aplicação de álcool $70 \%$ pós-lavagem e antes da secagem. Posterior à secagem, segue-se a embalagem dos óculos manualmente.

No período entre novembro de 2014 e novembro de 2015 foram analisadas 555 amostras, sendo que $55,9 \%$ destas corresponderam a óculos não higienizados e 44,1 $\%$ a óculos higienizados. Dentre as amostras de óculos higienizados, $67,3 \%$ foram provenientes de higienização manual e $33,7 \%$ por higienização automatizada. Ao todo, foram identificados 12 diferentes tipos de microrganismos, sendo Staphylococcus coagulase negativo $(31,2 \%)$ o mais frequente nas amostras (Tabela 1). 
Avaliação microbiológica das técnicas de higienização empregadas em óculos 3D, reutilizáveis em cinemas de Salvador, Bahia

Tabela 1 - Resultados das análises bacteriológicas e colimétricas em óculos 3D de cinemas em Salvador - BA, segundo condição e forma de higienização empregada.

\begin{tabular}{lcccc}
\hline \multirow{2}{*}{ Variáveis } & \multicolumn{3}{c}{ Análise } \\
\cline { 2 - 5 } & \multicolumn{2}{c}{ Bacteriológica } & \multicolumn{2}{c}{ Colimétrica } \\
\hline Condição de higienização & $\mathrm{N}$ & $\%$ & $\mathrm{n}$ & $\%$ \\
\hline Higienizado & 245 & 44,1 & 24 & 50 \\
Não higienizado & 310 & 55,9 & 24 & 50 \\
Resultados & & & & \\
Positivos & 233 & 42 & 6 & 12,5 \\
Negativos & 322 & 58 & 42 & 87,5
\end{tabular}

Microrganismos identificados

\begin{tabular}{lcccc} 
A. lowffii & 8 & 1,4 & ---- & ---- \\
\hline B. mallei & 1 & 0,2 & ---- & ---- \\
\hline Bacillus sp. & 1 & 0,2 & ---- & ---- \\
\hline Complexo B. cepácia & 1 & 0,2 & ---- & ---- \\
\hline Corynebacterium sp. & 12 & 2,2 & ---- & ---- \\
\hline Enterobacter aerogenes & 1 & 0,2 & ---- & ---- \\
\hline K. pneumoniae & 14 & 2,5 & ---- & ---- \\
\hline Micrococcus sp. & 22 & 4,0 & ---- & ---- \\
\hline P. pseudoalcaligenes & 4 & 0,7 & ---- & ---- \\
\hline S. aureus & 25 & 4,5 & ---- & ---- \\
\hline S. coagulase negativo & 173 & 31,2 & ---- & ---- \\
\hline Streptococcus sp. & 8 & 1,4 & ---- & ---- \\
\hline Coliforme $^{*}$ & ---- & ---- & 6 & 12,5 \\
\hline
\end{tabular}

Tipo de higienização

\begin{tabular}{lcccc} 
Manual & $165^{* *}$ & 67,3 & $14^{* *}$ & 58,3 \\
Automatizada & $80^{* *}$ & 32,7 & $10^{* *}$ & 41,7 \\
\hline
\end{tabular}

${ }^{\star}$ A classificação como coliforme foi realizada apenas para a análise colimétrica.

** Os valores fazem parte do total de amostras higienizadas

Observa-se que o percentual de amostras positivas para microrganismos nos óculos não higienizados $(54,5 \%)$ foi mais que duas vezes maior do que o percentual de contaminação nas amostras higienizadas $(25,7 \%)$, sendo essa diferença estatisticamente significante $(p<0,0001)$ (Tabela 2). Identifica-se ainda que a higienização contribuiu significativamente para redução da contaminação por Staphylococcus coagulase negativo $(p<0,0001)$ e considerável redução de contaminação por Corynebacterium sp. (p: 0,05). 
Tabela 2 - Comparativo entre amostras bacteriológicas de óculos 3D de cinemas em Salvador - BA, considerando a condição de higienização.

\begin{tabular}{lccc}
\hline \multirow{2}{*}{ Variáveis } & \multicolumn{3}{c}{ Condição de Higienização } \\
\cline { 2 - 4 } & Higienizado n(\%) & Não higienizado $n(\%)$ & Valor de P \\
\hline Presença de bactéria & & & \\
Positivo & $63(25,7 \%)$ & $170(54,5 \%)$ & $<0,0001$ \\
Negativo & $182(74,3 \%)$ & $140(45,2 \%)$ & \\
Bactérias identificadas & & & \\
A. lowffii & $1(0,4 \%)$ & $7(2,3 \%)$ & $0,0,68^{*}$ \\
B. mallei & $1(0,4 \%)$ & $0(0 \%)$ & $0,441^{*}$ \\
Bacillus sp. & $1(0,4 \%)$ & $0(0 \%)$ & $0,441^{*}$ \\
complexo B. cepácia & $0(0 \%)$ & $1(0,3 \%)$ & $0,559^{*}$ \\
Corynebacterium sp. & $2(0,8 \%)$ & $10(3,2 \%)$ & 0,053 \\
Enterobacter aerogenes & $0(0 \%)$ & $1(0,3 \%)$ & $0,559^{*}$ \\
K. pneumoniae & $4(1,6 \%)$ & $10(3,2 \%)$ & $0,181^{*}$ \\
Micrococcus sp. & $11(4,5 \%)$ & $11(3,5 \%)$ & $0,363^{*}$ \\
P. pseudoalcaligenes & $1(0,4 \%)$ & $3(1 \%)$ & $0,405^{*}$ \\
S. aureus & $7(2,9 \%)$ & $18(5,8 \%)$ & $0,071^{*}$ \\
S. coagulase negativo & $42(17,1 \%)$ & $131(42,3 \%)$ & $<0,0001$ \\
\hline Streptococcus sp. & $4(1,6 \%)$ & $4(1,3 \%)$ & $0,505^{*}$ \\
\hline * teste exato de Fisher & &
\end{tabular}

${ }^{*}$ teste exato de Fisher

Quanto ao método de higienização, não foram identificadas diferenças estatisticamente significantes na frequência de contaminação, tanto para higienização manual como na automatizada ( $p: 0,505)$. No entanto, para Staphylococcus aureus, parece existir alguma influência quando a higienização é automatizada (p: 0,060), com redução do percentual de contaminação por esse agente (Tabela 3). 
Avaliação microbiológica das técnicas de higienização empregadas em óculos 3D, reutilizáveis em cinemas de Salvador, Bahia

Tabela 3 - Comparativo entre amostras bacteriológicas de óculos 3D de cinemas em Salvador - BA, considerando a forma de higienização empregada.

\begin{tabular}{llll}
\hline \multirow{2}{*}{ Variáveis } & \multicolumn{2}{l}{ Tipo de higienização } & \\
\cline { 2 - 4 } Presença de bactérias & Manual $\mathrm{n}(\%)$ & Automatizada $\mathrm{n}(\%)$ & Valor de P \\
\hline Positivo & $42(25,5 \%)$ & $21(26,3 \%)$ & $0,505^{*}$ \\
Negativo & $123(74,5 \%)$ & $59(73,8 \%)$ & \\
Bactérias identificadas & & & \\
A. lowffii & $1(0,6 \%)$ & $0(0 \%)$ & $0,673^{*}$ \\
B. mallei & $1(0,6 \%)$ & $0(0 \%)$ & $0,673^{*}$ \\
Bacillus sp. & $1(0,6 \%)$ & $0(0 \%)$ & $0,673^{*}$ \\
complexo B. cepácia & $0(0 \%)$ & $0(0 \%)$ & ---- \\
Corynebacterium sp. & $1(0,6 \%)$ & $1(1,3 \%)$ & $0,547^{*}$ \\
Enterobacter aerogenes & $0(0 \%)$ & $0(0 \%)$ & ----- \\
K. pneumoniae & $4(2,4 \%)$ & $0(0 \%)$ & $0,203^{*}$ \\
Micrococcus sp. & $7(4,2 \%)$ & $4(5 \%)$ & $0,509^{*}$ \\
\hline P. pseudoalcaligenes & $1(0,6 \%)$ & $0(0 \%)$ & $0,673^{*}$ \\
S. aureus & $7(4,2 \%)$ & $0(0 \%)$ & $0,060^{*}$ \\
\hline S. coagulase negativo & $26(15,8 \%)$ & $16(20 \%)$ & $0,257^{*}$ \\
\hline Streptococcus sp & $1(0,6 \%)$ & $3(3,8 \%)$ & $0,103^{*}$ \\
\hline
\end{tabular}

${ }^{*}$ teste exato de Fisher

Com relação ao resultado das análises de coliformes, em razão de adversidades enfrentadas no andamento da pesquisa, foi possível somente a investigação em 48 amostras distribuídas proporcionalmente entre aquelas higienizadas e não higienizadas. Em termos gerais, 83,3\% das amostras em conjunto apresentaram crescimento de bactérias não coliformes, $12,5 \%$ apresentaram crescimento de coliformes e não coliformes, concomitantemente, e 4,2\% tiveram resultado negativo (Tabela 1 ).

A análise permitiu observar que o percentual de contaminação por coliforme é maior em amostras não higienizadas ( $p: 0,032$ ), entretanto, não foi encontrada diferença estatisticamente significante na frequência de contaminação $(p: 0,583)$ seja após a lavagem manual ou automatizada (Tabela 4). 
Tabela 4 - Resultados comparativos da análise colimétrica quanto a condição e método de higienização.

\begin{tabular}{|c|c|c|c|c|c|}
\hline \multirow{3}{*}{ Variáveis } & \multicolumn{5}{|c|}{ Resultados } \\
\hline & \multicolumn{2}{|c|}{ Negativos } & \multicolumn{2}{|c|}{ Coliformes } & \multirow[t]{2}{*}{ Valor de $\mathrm{P}$} \\
\hline & $\mathrm{n}$ & $\%$ & $\mathrm{n}$ & $\%$ & \\
\hline \multicolumn{6}{|c|}{ Condição de higienização } \\
\hline Higienizado & 24 & $100 \%$ & 0 & $0 \%$ & \multirow{2}{*}{0,032} \\
\hline Não higienizado & 18 & $75 \%$ & 6 & $25 \%$ & \\
\hline
\end{tabular}

Tipo de higienização

\begin{tabular}{l|l|l|l|l|l}
\hline Manual & 14 & $100 \%$ & ---- & ---- & \multirow{2}{*}{$0,388^{*}$} \\
\cline { 1 - 5 } Automatizada & 10 & $100 \%$ & ---- & ---- & \\
\hline
\end{tabular}

* teste exato de Fisher

Obs: É válido ressaltar que 40 amostras apresentaram crescimento atípico de colônias de bactérias que não foram identificadas e não podem ser consideradas como coliformes.

\section{DISCUSSÃO}

Bactérias Gram-positivas como Staphylococcus epidermidis, Staphylococcus aureus, Corynebacterium sp., Streptococcus sp., Micrococcus sp. e Propionibacterium $s p$., as quais, a exceção de Propionibacterium sp., foram encontradas com mais frequência nas amostras analisadas, constituem a microbiota natural da superfície ocular formada após o nascimento, considerando que Staphylococcus epidermides é de estirpe coagulase negativo.(11) Essas bactérias são encontradas inclusive em superfície ocular sadia sem causar danos. ${ }^{(12,13)}$ Entretanto, podem ser consideradas patógenos potencialmente causadores de infecções em seres humanos, principalmente quando relacionados ao uso de dispositivos médicos. ${ }^{(14)}$ Por conseguinte, bactérias Gram-negativas como Acinetobacter $s p$. são tidas por alguns autores como microbiota transitória por serem menos encontradas em locais do corpo como a superfície dos olhos. ${ }^{(15)}$

Apesar de constituir a microbiota, em determinadas condições, essas bactérias não patogênicas, a depender do estado imunológico do hospedeiro, podem se tornar patogênicas. ${ }^{(11,13,16)}$ Sendo assim, as bactérias identificadas na superfície dos óculos $3 \mathrm{D}$ podem oferecer riscos à saúde de seus usuários quando estes apresentam condições não favoráveis à homeostasia da microbiota ocular, como em casos de imunodepressão, além de estarem envolvidas em processo de doenças altamente contagiosas como conjuntivite bacteriana causada por Staphylococcus aureus e Staphylococcus coagulase negativo, por exemplo, tendo esta última apresentado a maior frequência dentre o total de amostras (Tabela 1). ${ }^{(17,18)}$

Quanto ao processo de higienização, Giust et. al. ${ }^{3}$ descreveram em seu estudo em óculos 3D que existe uma diferença significante na média de contaminação por bactérias mesófilas e Staphylococcus coagulase positivo entre óculos 3D higienizados 
e após o uso, demonstrando que a higienização deste reduz a presença desses microrganismos, concordando com os resultados do presente estudo, onde a frequência de amostras contaminadas entre os óculos higienizados foi menor que nos óculos não higienizados (Tabela 2).

Quanto às técnicas de higienização empregadas, manual ou automatizada, não houve diferença significativa entre as frequências de amostras positivas e negativas (Tabela 3). Porém, Giust et. al. ${ }^{3}$ observaram em seu estudo que se aplicados os padrões da American Public Health Association (APHA) na contagem de colônias presentes nos óculos analisados, todas as amostras higienizadas por método manual se classificariam como própria para uso, enquanto que por método automático apenas $10 \%$ seriam consideradas impróprias, por apresentarem quantidade de colônias superior ao permitido.

Basman et. al. ${ }^{19}$ também mencionaram em seu estudo com escovas de dentes que, dentre outros métodos de higienização, provavelmente o automatizado seja aquele que promova a menor redução da carga microbiana. Sendo assim, pode-se inferir que se fosse feita uma análise quantitativa dos microrganismos presentes nas amostras, em vez de apenas sua frequência, talvez fosse observada uma maior diferença quanto a capacidade de remoção entre métodos de higienização no presente estudo. Contudo, ainda assim a higienização automatizada apresenta efeito de diminuição da contaminação.

Apesar da baixa significância estatística, a maior frequência de Staphylococcus aureus após higienização manual parece não ter relação com o método de higienização, pois em outros estudos não foram relatadas diferenças significantes quanto ao método de higienização empregado na remoção de Staphylococcus aureus. ${ }^{(3,19)}$ Todavia, é possível que a frequência encontrada seja fruto de contaminação cruzada a partir das mãos dos manipuladores envolvidos no processo de higienização e armazenamento dos óculos. ${ }^{(20)}$

Quanto à análise de coliformes, observou-se que este grupo de bactérias esteve presente apenas em óculos não higienizados sendo aceitável a concordância com Giust et. al. ${ }^{3}$ que não encontraram este grupo de bactérias em suas análises.

O presente estudo apresentou algumas limitações quanto às técnicas de análise empregadas e ao tamanho da amostra da avaliação colimétrica. Apesar do tamanho amostral da análise bacteriológica ter sido um fator favorável ao estudo, a técnica utilizada apenas demonstrou presença e ausência de microrganismo, não sendo realizada sua quantificação. Caso fosse feito poderia demonstrar resultados mais robustos e talvez diferentes do encontrado, sendo possível comparar a carga microbiana presente nos óculos antes e após a higienização e se existe diferença significativa na redução da carga microbiana quando se aplica diferentes técnicas de higienização. Além disso, se permitiria também uma melhor avaliação dos riscos relacionados ao uso dos óculos 3D contaminados, levando em consideração a carga microbiana que esses objetos podem carregar. Quanto à análise colimétrica, imprevistos no curso da pesquisa não permitiram maior tamanho da amostra, o que pode ter se tornado um fator limitante aos resultados. 
Diante da escassez de informações sobre assunto, se entende que o presente trabalho pode servir como incentivo ao desenvolvimento de outros estudos voltados para a análise da microbiota em 3D de cinemas, tendo em vista que muito pouco ainda se conhece a respeito. Talvez no futuro estudos mais consistentes possam trazer maiores contribuições para se avaliar os riscos envolvidos no reuso desses óculos, levando assim a uma maior proteção e promoção da saúde individual e coletiva.

\section{CONCLUSÃO}

A partir dos resultados expostos, verificou-se que a higienização empregada nos cinemas, seja manual ou automatizada apresenta efeito significativo na redução da frequência de microrganismos em óculos 3D, utilizados nos cinemas de Salvador. Observou-se também que existe uma maior frequência de contaminação por Staphylococcus coagulase negativo, Staphylococcus aureus, Micrococcus sp. e Corynebacterium sp., as quais já foram descritas como pertencentes à microbiota da superfície ocular e da pele humana, mas que podem apresentar patogenicidade sob determinadas condições de saúde.

\section{AGRADECIMENTOS}

À Secretaria da Saúde de Salvador (SMS) e Escola Bahiana de Medicina e Saúde Pública pelo suporte; a Karina L. R. Queiroz, Kédima B. Pereira, Maria Aparecida A. Dias e demais técnicos da Vigilância Sanitária do Distrito Sanitário Cabula/Beirú pelo apoio; ao Laboratório Central de Salvador (LACEN-Salvador), representado pela Coordenadora Olivete B. dos Reis e técnicas Edna Maria dos S. Rêgo, Silvia de A. Cruvinel e Naize N. P. da Silva pela realização das análises microbiológicas. Finalmente ao professor Edson Ruy da Silva Félix da Escola Bahiana de Medicina e Saúde Pública, idealizador e coordenador desta pesquisa, e a todos aqueles que direta ou indiretamente contribuíram para que fosse possível a realização deste trabalho.

\section{REFERÊNCIAS}

1. Suppia AO. Monstro brasileiro revive em 3D. Cienc Cult. [Internet]. 2007 [acesso em 2019 mai 06]; 59(2): 57-9. Disponível em: http://cienciaecultura.bvs.br/scielo.php?script=sci_arttext\&pid=S000967252007000200024

2. Christofoli EP. O Renascimento do 3d. Contemp. [Internet]. 2011 [acesso em 2019 mai 06]; 9(17): 138-45. Disponível em: https://www.e- 
publicacoes.uerj.br/index.php/contemporanea/article/view/1659/1588

3. De Giusti M, Marinelli L, Ursillo P, Del Cimmuto A, Cottarelli A, Palazzo C, et al. Microbiological safety of glasses dispensed at 3D movie theatres. Eur J Public Health [Internet]. 2015 [acesso em 2019 mai 06]; 25(1): 139-41. Disponível em: https://academic.oup.com/eurpub/article-lookup/doi/10.1093/eurpub/cku019

4. Brasil. Congresso Nacional. Projeto de lei N. 3.505, de 2012. Dispõe sobre a obrigatoriedade de filmes em terceira dimensão (3D). 2012.

5. Salvador. Lei $n^{\circ} 8.642$, de 15 de agosto de 2014. Dispõe sobre a obrigatoriedade de higienização dos óculos utilizados para filmes em terceira dimensão (3D), no âmbito do Município de Salvador. Diário oficial do município. Salvador, Ba; 2014 ago 16.

6. Smith SI, Opere B, Goodluck HT, Akindolire OT, Folaranmi A, Odekeye OM, et al. Antibiotic susceptibility pattern of Staphylococcus species isolated from telephone receivers. Singapore Med J. [Internet]. 2009 [acesso em 2019 mai 06]; 50(2): 208-11.Disponível em: http://www.ncbi.nlm.nih.gov/pubmed/19296038

7. Uesugui E, Cypel-Gomes MC, Atique D, Goulart DG, Gallucci FR, NishiwakiDantas MC, et al. Identificação laboratorial dos patógenos oculares mais freqüentes e sua suscetibilidade in vitro aos agentes antimicrobianos. Arq Bras Oftalmol. [Internet]. junho de 2002 [citado 6 de maio de 2019];65(3):339-42. Available at: http://www.scielo.br/scielo.php?pid=S000427492002000300011\&script=sci_abstract\&tlng=pt

8. Custódio J, Alves JF, Silva FM, von Dolinger EJI, dos Santos JGS, Brito D von D. Avaliação microbiológica das mãos de profissionais da saúde de um hospital particular de Itumbiara, Goiás. Rev Ciênc Méd. [Internet]. 2009 [acesso em 2019 mai 06]; 18(1): 7-11. Disponível em: https://seer.sis.puccampinas.edu.br/seer/index.php/cienciasmedicas/article/view/649/629

9. Kramer A, Schwebke I, Kampf G. How long do nosocomial pathogens persist on inanimate surfaces? A systematic review. BMC Infect Dis. [Internet]. 16 de agosto de 2006 [citado 6 de maio de 2019];6(1):130. Available at: https://bmcinfectdis.biomedcentral.com/articles/10.1186/1471-2334-6-130

10. Merriman E, Corwin P, Ikram R. Toys are a potential source of cross-infection in general practitioners' waiting rooms. Br J Gen Pract. [Internet]. 2002 [acesso em 2019 mai 06]; 52(475): 138-40. Disponível em: http://www.pubmedcentral.nih.gov/articlerender.fcgi?artid=PMC1314220

11. Netto AA, Amaro AC, Daguano CR. Avaliação da contaminação bacteriana dos cones de aplanação dos tonômetros de Goldmann em uso em consultórios e hospitais da Grande Florianópolis. Arq Catarin Med. 2007; 36: 45-50.

12. Perkins RE, Kundsin RB, Pratt M V., Abrahamsen I, Leibowitz HM. Bacteriology of normal and infected conjunctiva. J Clin Microbiol. 1975; 1(2): 147-9. 
13. Dong Q, Brulc JM, lovieno A, Bates B, Garoutte A, Miller D, et al. Diversity of Bacteria at Healthy Human Conjunctiva. Invest Opthalmol Vis Sci. [Internet]. 2011 [acesso em 2019 mai 06]; 52(8): 5408-13. Disponível em: http://iovs.arvojournals.org/article.aspx?doi=10.1167/iovs.10-6939

14. Teixeira CF. Estafilococos coagulase-negatica - um risco para a saúde pública [tese]. [Internet]. Rio de Janeiro: Instituto Nacional de Controle de Qualidade em Saúde, Fundação Oswaldo Cruz; 2009 [acesso em 2019 mai 06]. Disponível em: https://www.arca.fiocruz.br/handle/icict/4009

15. Sankaridurg PR, Markoulli M, de la Jara PL, Harmis N, Varghese T, Willcox MDP, et al. Lid and Conjunctival Micro Biota During Contact Lens Wear in Children. Optom Vis Sci. 2009; 86(4): 312-7.

16. Lu LJ, Liu J. Human Microbiota and Ophthalmic Disease. Yale J Biol Med. [Internet]. 2016 [acesso em 2019 mai 06]; 89(3): 325-30. Disponível: http://www.pubmedcentral.nih.gov/articlerender.fcgi?artid=PMC5045141

17. Silva JO, da Silva P, Carneiro AMM, Carloni MC, Medeiros MIC. Investigação da Conjuntivite Bacteriana na Região de Ribeirão Preto, SP. NewsLab. 2012; 113: 186-96.

18. Teweldemedhin M, Saravanan M, Gebreyesus A, Gebreegziabiher D. Ocular bacterial infections at Quiha Ophthalmic Hospital, Northern Ethiopia: an evaluation according to the risk factors and the antimicrobial susceptibility of bacterial isolates. BMC Infect Dis. [Internet]. 2017 [acesso em 2019 mai 06]; 17: 207. Disponível em:

http://bmcinfectdis.biomedcentral.com/articles/10.1186/s12879-017-2304-1

19. Basman A, Peker I, Akca G, Alkurt MT, Sarikir C, Celik I. Evaluation of toothbrush disinfection via different methods. Braz Oral Res. [Internet]. 2016 [acesso em 2019 mai 06]; 30(1): 716. Disponível em:

http://www.scielo.br/scielo.php?script=sci_arttext\&pid=S1806$83242016000100203 \&$ Ing=en\&tIng=en

20. Maia ICP, Monteiro MAM, da Fonseca JL, Coelho MRL, Lopes SLC. Análise da contaminação de utensílios em unidades de alimentação e nutrição hospitalar no município de Belo Horizonte-MG. Alim Nutr. [Internet]. 2011 [acesso em 2019 mai 06]; 22(2): 265-71. Disponível em: http://servbib.fcfar.unesp.br/seer/index.php/alimentos/article/view/1363/1117

Artigo recebido em: 15/05/2019

Artigo aprovado em: $24 / 08 / 2020$

Artigo publicado em: 28/08/2020 